\title{
Recognizing Criminal Behavior (Filicide) of Persons Diagnosed with Mental Illness: An Analysis on the Intentionality and a Philosophical Disclosure on Ethics and Morality
}

\section{Tang B*}

MD, MPH, DABNS(1981), Research Consultant Emeritus, New York College of Traditional Chinese Medicine, Minolia, NY, USA

"Corresponding author: Tang B, New York College of Traditional Chinese Medicine, Minolia, NY, USA, Tel: 15164268010; E-mail: prof.bing@gmail.com Received date: May 05, 2015; Accepted date: September 28, 2015; Published date: October 02, 2015

Copyright: $@ 2015$ Tang B. This is an open-access article distributed under the terms of the Creative Commons Attribution License, which permits unrestricted use, distribution, and reproduction in any medium, provided the original author and source are credited.

\begin{abstract}
In this article, two case examples of criminal behavior in the USA are analyzed. There is a discussion on intentionality. A brief introduction to Filicide is made. Note that in respects, the impressions of trials forecasted by the media have great influence, fortifying public impression of the law rather than communication with the legal system per se. A disclosure on philosophical basis, together with Kant's theories, is provided. Because Kant passed away before the notion of intentionality was introduced, what is new in this article to add in knowledge is to correlate Kant's theories with these two perpetrators' behavior. A reflection with a practical application of Kant's theories constitutes the core component of theory in this article. The reflection includes analyses of our own lives in order to re-assess our attitude in dealing with each other and with youngsters.

The potential for criminality should be identified early in patient care. A prompt detection should be enacted to identify the potential for criminal violence. Appropriate staffing and protective measure should be enacted. A thoughtful team approach by both medical practitioners and their institutions, involving clinicians, non-clinicians, philosophers and scientists should be pursued. The conclusion stresses the importance of an early identification of a person diagnosed with mental illness who has also committed crime or crimes. Such an identification should be preceded by a well thought out crisis-recognition-process, appropriate staffing and secured protective measures.
\end{abstract}

Keywords: Criminal behaviour; Ethics; Kant; Morality; Philosophical disclosure; A person diagnosed with mental illness.

\section{Introduction}

Two US crime cases are being cited in this article. These two crimes of filicide are then analyzed. The analysis demonstrates how two persons acted in terms of the function of their respective mind.

These cases are used as a basis for further discussion. Philosophical positions such as Dennett's and Brenato's that pertain to the discussion are offered with emphasis to its theoretical implications. The application of the Kantian theory also follows the philosophical discourse. An account of Kant's moral philosophy is offered as well. A brief review of Kantian writing, particularly his categorical imperatives and theory of the mind are employed to facilitate an understanding of the issues and their variables (factors). To accomplish this aim, the author uses several related topics (notable for their interconnection and their respective selected arrangement) and their probable answers, to reinforce the argument.

\section{Related Work}

\section{A brief introduction of the relationship between the mind and brain}

Most people perceive ideas as emotions and intangible feelings. Can it be assumed that one human being's idea (e.g: goodwill) or category (e.g: the ability to classify) is understood correctly by another?
Many philosophers will challenge the assumption that the human mind equates its ideas. In 1637 Rene Descartes originally illustrated certain knowledge. Descartes argued, as an omnipotent negative tried to deceive him into thinking that he existed when he actually did not. Descartes would have to exist in order to be deceived. Hence, when he thought, he existed.

Moreover, Descartes argued, "I think, therefore, I am." This expresses intuition, not reason, and it is thus unquestionable. The above, as well, explains the difference between the mind and the intuition, that is, the immediate direct idea.

On the other hand, ideas are diverse when their comprehension is varied. Diverse idea can be compatible or not. Human ideas are diverse.

The bottom line is that human ideas, using the appropriate techniques, seem that it can be superficially quantified, calculated, classified and measured. Definite boundaries of the human idea appear to exist.

The territory of ideas is "not infinite." The quantity of ideas that human beings possess appears to be "finite". The idea of human mind appears to be the collective aspects of intellect and consciousness, which is manifested in combination of thought, perception, emotion, will, and imagination.

In fact, the conscious and self-conscious functions of the brain may be collectively referred to as the mind. The mind is referred as the corporate aspects of intellect and consciousness, which are manifested in some combination of thought, perception, emotion, will, and 
imagination as aforesaid. Nevertheless, there still are two key arguments existing:

The human mind is not equivalent to the human ideas, while the mind mapping and brain mapping are not the same.

With the aforementioned, almost no one is absolutely certain on how the mind and the brain are related with each other.

Are there not the body-brain, brain-mind, and mind-matter dualities in an interfacing triad? These questions appear to be dealt with philosophy, culture, society and bioethics.

Philosophers are very interested in whether the "mind" (a la Kant) could indeed be "categorized". Whereas most of them would agree that the mind does "categorize", but they do not agree on what constitutes the most basic categories.

On the other hand Galen Strawson, in his book entitled Mental Reality, argues that the answer to the characteristic features of the mental reality is the conscious experience, but not intellect, emblematic content, or internationality (Earle, 1983) as it is generally understood. Strawson further argues that much of the contemporary philosophy of the mind is still in a state of confusion due to positivism and its numerous progenies. This author agrees that we should consider to the nature of a mind, unwarranted primacy to the nonmental phenomena, publicly observable phenomena, and behavioral phenomena. Strawson has made such a careful, sensitive and imaginative treatment of some of the main conceptual issues in methods for the study of the mind's nature.

Is there any relationship between the mind and the behaviour? While most thinkers, and/or philosophers agree that there are other relationships between the mind and the behavior, and between the behavior and the culture, the problem is that most of the thinkers, and/or philosophers may not agree as to how these relationships could be fully described. Some thinkers consider the mind as essentially Tabular Rasa-a young mind not yet affected by the experience and is merely a repository of external effects on the mind. This view is shared by Locke [1], whose theory of knowledge asserts that the human mind is, from time of birth, a "blank slate" without any regulatory mechanism for processing data, both intrinsic and extrinsic Subsequently, accumulated data are processed through the formation and imprinting of the human sensory experience. This notion supports an essential Lockean empiricism. Therefore, to empiricists, the mind is a Tabula rasa, it is as if the mind is being written when we learn or experience the world in us and around us. Conversely, for the rationalists, the mind is like a computer, that is, the hardware, which already has some functions (innate ideas) before installation, downloading, and uploading of the software (experiences, specific knowledge, etc). For example, just as the premise of the "pedagogical century" in the 18th century, it regards the young individual as a Tabula rasa. (Breithaupt, F, 2005). Moreover, in recent time, Tabula rasa appears, as well, featured in Sigmund Freud's psychoanalysis [2-4].

\section{The Body-Mind Problem}

\section{The relationship between our conscious experience (or our mind) and our bodies}

Griffin performs an attractive dissection on the mind-body problem [5], and firmly declares that the mind-body problem is the vital issue for modern philosophy. In order to solve this problem, we must first well explain the relationship between our conscious experience (our mind) and our bodies. The fundamental component of realism is the "actual occasion", which has both spatial and chronological factors. Unfortunately our inner experiences have only chronological, but not spatial nature. Process philosophers rationalize their assertion on the existential premises that a human being can only actually appreciate the components constituting the material globe by similarity with our own experience, which become acquainted from within ourselves. In order to solve this problem, Griffin states the following:

The apparent difference in kind between our experience, or our 'mind', and the entities comprising our bodies is an illusion, resulting from the fact that we know them in two different ways: we know our minds from within, by identity, whereas in sensory perception of our bodies we know them from without [5].

Once we understand this, there is no reason to assume that our minds and our bodies are different in type. In the previously mentioned context, the link between our bodies and the mind is established.

While the idea that the individual can be altered remains, the power to affect this kind of alteration is now assigned merely to society, and is no longer attributed to the individual himself. Further, the power to alter has been extended to the totality of human nature. Under such a notion, one can, almost without limitation, mould the individual by changing his environment first, and then his sensory experience.

\section{A brief review of the related research of filicide}

In fact, few types of crime are as appalling-and disturbing-as filicide, in which a parent kills one or more of his or her children. Some people cannot picture a penalty severe enough for a parent who would commit such an act. Others find that that it is so unintelligible and they have no question about the parent's being insane at the time of committing the crime.

Forensic psychiatrist Phillip Resnick has developed a classification system for filicide based on the parent's motive. He describes the various types of filicide in his classification system and the likelihood of a successful insanity-defence in each [6].

He initially defines five types of filicide. In "altruistic" filicide, a parent (almost always a mother in this category) kills her child or children as a form of suicide. "These mothers see their children as a form of an extension of themselves, they do not want to leave a child motherless in a 'cruel' world as seen through their depressed eyes." On the other hand, in the second type of altruistic filicide a child is killed in order to end his or her real or imagined suffering." These mothers may project their own unacceptable symptoms onto the child," Resnick said. In "acutely psychotic" filicide, hallucinations, epilepsy, or delirium drives a parent to kill a child. Psychiatric evaluators will not find a "comprehensible motive" in this type of killing (according to Resnick). Resnick's third category involves "unwanted child" filicide, which includes homicides in which a parent no longer wants the child. "Fatal maltreatment" filicides fall into two types, he suggests. In one-the most common motive for child homicide in the United States-children die as the result of beating, and homicide is not the objective. The other type, which is extremely rare, he noted, occurs as the result of Munchausen syndrome by proxy. His fifth filicide motivation is "spouse revenge." This category includes cases in which parents murder their children to make their spouse suffer, most often in revenge for infidelity. In the following year, 1970, he added a sixth category, Neonaticide [6]. Noticeably, in the subset of altruistic filicide in which the killing is in fact an extended suicide attempt, severe depression may have 
deformed thinking "so that the mother believes her children will be better off in heaven with her..." This is akin to the explanation that Andrea Yates, one of the two perpetrators discussed in this paper, gave for murdering her own children. (Resnick was also an expert witness for the defense in that case.) The mother often believes she is doing what is "morally right for her child". In altruistic filicide cases, the success of an insanity plea hinges in large part on whether the insanity standard uses the word "appreciate" or "know" to characterize the parent's understanding of the wrongfulness to kill. Conversely, in the category of acutely psychotic filicide, "the parent may not know the nature and quality of the act," if it takes place during an epileptic seizure or delirium, according to Resnick. In evaluating a person who appears to fall into this category, evaluators "must always consider malingering," Resnick stated. Command hallucinations, such as obeying orders to kill from God or Satan, are involved.

That being mentioned, it is in this author's opinion that, under legal circumstances, intentionality must have a broad view of human responsibility. The law may be neutral (open to debate), but its interpretation is not.

On the other hand, it is worthwhile to mention that Capital jury project is a continuing program of research on the decision-making of capital jurors that was initiated in 1991 by a consortium of universitybased researchers with support from the National Science Foundation (NSF). Using data from the NSF, Sundby in his article takes a close observation within the jury room at the process by which capital juries arrive an undisputed verdict at the penalty phase. The legal process shows to be an attractive one. In his article, Sundby used the closing argument in the death penalty case of Susan Smith (Sundby SE).

Note Susan Smith was the mother, killed her two children by driving them into a lake and then trying to cast blame on a unidentified African American man. In his own article, Sundby concludes by examining how a closing argument may affect outcomes of that case.

In fact, when Katheryn Russell-Brown heard Susan Smith's tale that she had been carjacked by a young African American man, she was skeptical. In 1994, Smith told police that while stopped at a traffic signal, she was carjacked by an African American man who drove off with her infant and toddler boys in the back seat. 'Where would an African American man go with two small white children?' [7].

In reality, time-honored law is been viewed by most of us as a dependable branch our learning and on approach of arranging information, as well, a solution in which legality and confidence are developed. The law, we are informed, loves impartiality-but not engagement. However in these occasions, the work of the law applies not only in the familiar land of the official, ritualized space of the courthouse building; it is at present resembling as public sight-a type of document-drama in which dissimilar media impressions, both in print and in visual, describing how the law works. In respects, the impressions of trials forecasted by the media have great influence, and fortifying public impression of the law rather than communication with the legal system per se. Media demonstrations not only mould public impression of the law; they also create realism in this area which public dialogue takes place. Too frequently, especially through wellliked media, images and illustrations are maneuvered to modify. These pictures frequently speak in voices nosier and in more forcing tones than any ordinary daily dialogue [8].

Such an effect appears to be more distinct in the case of highly contentious and popular trials, such as that in the case of Susan Smith.
As a matter of fact, the law works as 'a kind of meta-narrative about the appropriate or sanctioned relations of power between groups and their individual members. Legal storytelling is not only directed to nor confined within the courtroom. The images and identities constructed through legal narratives are affirmed or rejected in the larger social context as well. To the extent that these narratives confound rather than illuminate, giving us distorted or partial images of our realities, and we then view the law as constructed by and projected through the media does not fulfill any critical function. As part of the central argument of this author, so as one writer has noted, "insofar as law serves this expressive function for society, it fails to meet its goals when the conversation it generates bears false witness to the experience it seeks to evaluate." We are then left with cultural narratives-often stereotypes-that tell us little more than what we have already believed' [8].

That been introduced and briefly reviewed, allow us now to concentrate on the two exampled cases as follows

\section{Case Presentations}

The following case presentations are stemmed from books and the media.

\section{Case example 1}

The first case is that of Ms. Andrea Yates, a married woman with four children. She had suffered from psychiatric illness prior to drowning her children. She was charged with first-degree murder but found innocent due to insan Andrea Yates [9] is a former Houston, Texas resident who killed her five young children on June 20, 2001 by drowning them in the bathtub in her house. She had been suffering for years with very severe postpartum depression and psychosis. Her case placed the M Naghten Rules, a legal test for sanity, under close public scrutiny in the United States. Yates 2002 conviction of capital murder and sentence to life in prison with the possibility of parole after 40 years was later overturned on appeality.

Andrea Yates' retrial for the murder of her five children (in 2001) began on 26 June 2006 in the US. A retrial was ordered because one of the prosecution's witnesses lied on the stand. Her defence team argued insanity. Ms. Yates was convicted of drowning her five children in order to save them from "being tormented by Satan" [10-12].

On July 26, 2006, a Texas jury found that Yates was not guilty by reason of insanity. She was consequently committed by the court to the North Texas State Hospital, Vernon Campus, a high-security mental health facility in Vernon, Texas. In January 2007, Yates was moved to a low security state mental hospital in Kerrville, Texas.

\section{Case example 2}

Susan Smith: The other case was that of Ms. Susan Smith, who also drowned her children. Her court case decision was very different. She was found guilty of first-degree murder. Smith drowned her children on 25 October 1994 after 'her boyfriend rejected her'. She killed her two boys, Michael, 3, and Alex, 14 months by driving her automobile into a lake while the children slept in their car seats. She was sentenced to life in prison. 


\section{A brief analysis of these two cases}

These two cases resulted in the death of seven children by drowning. Yet the working of the mind determined the guilt or innocence as the laws may be applied to each case respectively. Nevertheless, the states of mind of these two women at and/or immediately prior to the death of children were different.

\section{First of all, was Andrea Yates guilty of murdering?}

The gradation of her guilt, however, must depend on the circumstances. A verdict of not guilty is not the ethical way to deal with murder in this author's point of view. Some believes that our justice system has failed. Perhaps, first-degree murder is too much a punishment in the Yates case. Some feels that the justice system failed on several counts. First, it failed to take into consideration of the gradation of her guilt. Second, it also failed in terms of technicalities. Perhaps some lawyers and judges are frustrated with technicalities of the justice system. Some may argue that the lack of intentionality is brought by the context - the law. The law is supposed to be objective while ascriptions of intentionality are subjective.

The law (unlike science) does not apply to predictions, only in events and facts after all, Ms. Andrea Yates was a married woman with four children. She had suffered from psychiatric illness prior to murdering her children by drowning them. She was charged with firstdegree murder but found innocent due to insanity.

On the other hand, Susan Smith, after being 'rejected by her boyfriend', drowned her own children. Ms Susan Smith drowned her children on 25 October 1994 'after her boyfriend rejected her. She killed her two boys by driving her automobile into a lake while the children slept in their car seats.

\section{Discussion}

\section{Intentionality}

Intentionality holds the human mind responsible. As aforementioned, intentionality must have a bold view of human responsibility. It is important to note at this point, that the law may be neutral (open to debate), but its interpretation is not. Intentionality in fact is the property of mental states, something outside the mind; the synonym for intentionality is "direction of thoughts" or "inclination of ideas".

On the other hand, "aboutness" is a term used in library and information science, linguistics, philosophy of language, and philosophy of mind. Among them, in philosophy it has been often considered, it as a synonymous with intentionality, perhaps since John Searle. Philosophers of mind and psychologists are both concerned with regard to 'aboutness'. For instances, there are work with the psychological or intentional aboutness (John Searle, 1983) and language of thought [11-13].

As to the aboutness of the two perpetrators in the two examples reported and discussed as aforementioned in this article, at a first glance, it appears that both Andrea Yates and Susan Smith 'intentionally' chose to harm others. By not taking intentionality seriously, in general concept, most people appear not take ethics gravely.
Nevertheless, there appears to be a connection between aboutness and epistemology. Noticeably, epistemology per se is very much about both objectivity and subjectivity.

That discussed, as Kant passed away before the notion of intentionality was introduced, no direct relation between Kantian theory and the theory of intentionality can be directly addressed over here. It appears that possible indirect links should be an object of a separate study other than that of this one.

In this article, it is introduced that knowledge is required to correlate part of Kant's theories, which will be presented in the latter sections.

According to Aquinas and Freeman respectively, on the philosophical sense of Intentionality, it appears to be merely a special case of features of mental states; but in a profound way, the mental states and intentionality appear to be related to each other.

Dennett believes that intentionality is ascribed to almost anything (Dennett, 1981, 1996). In contrast, Searle suggests that intentionality really exists [11]. This does not exclude the possibility that we may sometimes ascribe it erroneously. For example, if one assumes that some objects are living, and observes a mechanical cat, he may erroneously classify it as a living being. From Dennett's point of view, one could talk about "live stance", that is, there is no life as such but only a stance to it. Most people, (including Dennett himself) believe that there are living object in reality. Likewise, Searle has even suggested in the reality of intentionality. Nevertheless, it is unfortunate that the two words, intention and intentionality, are so similar in English. Brentano introduced the term intentionality directly from Latin [14-17], and Dennett devotes many pages to the characteristic differences among the following THREE terms: intention, intentionality, and, finally, intensionality. The last term, intensionality, is merely a linguistic one, which is meaning those aspects of interpretation are open for discussion. The term, intensionality, sheds little lights on the differentiations between the two perpetrators of killing in the US as aforementioned.

Jordan and Ghin claim that intentionality is a property of all living beings, including prokaryocytes [15,18-20]. Hence, one can hardly observe a legal application of the intentionality theory. On the contrary, as the definition of intentionality concerns "mental states", and can be applied for any discipline working with the notion of mental states, e.g., psychology, philosophy, and/or psychiatry.

Though Dennett clearly distinguishes between intentionalty and intention, he implies intentionality instead of intention in his "Intentional stance" theory. For example, if we say that "my computer is tired", we don't mean to accuse the computer in a court, we donot imply the computer's responsibility and choice. In fact, we would assume the responsibility of the programmer, that is, a human person. According to Dennett, there is nothing mysterious about the intentions and conscious feelings toward others. We sometimes assign feelings or intentions to non-human things. Dennett recommends that we might say, for example, our personal computer is a bit tired today. At the end of the day, our view of human beings is just an adaptation-a much more complex adaptation. Thus, why do we hesitate to assign human quality to non-human things? In that passage, Dennett clearly means INTENTIONS, NOT INTENTIONALITY $[21,22]$. Further, he agrees that ascription of intentions to non-human things is allegorical, or metaphorical. He proceeds as if he assumes that there is no significant difference between a direct meaning of a word (e.g., his coat 
is black) and a metaphorical using (e.g., his conscience appears to be in darkness).

One might not completely agree with the aforementioned Dennett's statement, and might even challenge it as a straw-man's argument. The issue appears to arise from a suggestion that humans tend to ascribe intentions. Two examples follow.

People who are paranoid ascribe intentions to other people (and things) in completely irrational ways (This author admits that to someone, the aforementioned might be somewhat an overstatement.)

Conspiracy theorists ascribe intentions in the form of conspiracy. The former, paranoid people, and the latter, conspiracy theorists, do not simply apply intentions to other people.

Indeed, paranoid patient understands very well that everybody (including himself) possesses intentions, but that at the same time, everybody (including himself) makes numerous unintentional acts like coughing, speaking sometimes louder, sometimes less loud, etc. However, when one is within his delusional thinking, he denies that other people's actions can be unintentional sometime too [23-25]. In other words, what makes paranoia is not ascribing intentions but denying non-intentional actions.

In addition, there is an example supporting a person's disagreement with an assertion that humans tend not to ascribe intention to other humans. One would call such an argument a 'straw man'-in order to develop a scholar's book/argument to argue, but really not a thing worthy to argue about, at least in this author's opinion. That said, general consensus on Ms Andrea Yates' case is that any mother would have to be in a delusional/psychotic state in order to kill her own children, and she would have been unable to tell the difference between right and wrong, morally, legally, negligently, and so on. Hence, the 'bipolar made me do it' syndrome appeared to be a test of the current public attitudes on mental illness [26-28].

Contrarily, ancient Egyptian sources assumed the ability of humans to free choice. But this ability is not, in contrast to intentionality, a property of all living beings (as Jordan and Ghin, as well, Jordan believe), of all mental states (as Brentano believed) nor the property of most mental states (as Dennett, Searle and most contemporary authors believe). But this ability is not, in contrast to intentionality, a property of all living beings (as Jordan and Ghin, as well, Jordan believe), of all mental states (as Brentano believed) nor the property of most mental states (as Dennett, Searle and most contemporary authors believe). It is limited to a very small circle of living beings that are able to stop their immediate activity in the world (i.e., behaviour) and to "play forward" this behaviour as a symbolic game $[29,30]$. This playing-forward is human reflexive thinking, and the small circle includes some adults.

How exactly should the line be drawn between those who are able to have this form of covert behaviour (and, hence, are guilty when they broke a law), and those who are not (and, hence, "insane"), is open to debate. An issue such as this one is largely a psychiatric issue, which should not be mixed up with philosophical issues, just as the diagnosis of coma-loss of consciousness, is a medical issue, and not a philosophical one.

\section{An Emphasis on the Writings of Immanuel Kant's Synthesis (without involving 'Intentionality')}

In this discussion, there is philosophical disclosure with an emphasis on the writings of Immanuel Kant's synthesis. Kant aspires to create a grand synthesis between sense knowledge and intellectual knowledge, which is in turn between the human's theoretical and practical activities. The transcendentalism is Kant's method to achieve this goal. In this endeavor, Kant attains remarkable outcome: the harmony of human cognition, its requirement and universality, the importance of the a priori, the absoluteness of the moral imperative, the transcendental issues, etc. Kant's achievement and contribution to issues involved in this article merit our review. A brief review may help us understand the issues discussed in this article, and to explain the factors involved [31,32]. Kant's contribution are: morality, ethics, good will, obligation, autonomy, respect, persuasion on the principle, justice, on physicians' treating people as an aim for physicians themselves, etc. Fundamentally, based on pure reason, Kant's categorical Imperative leads us to consider what is to be accomplished. "Categorical" is solely manifested by reason, and nothing else. To follow this imperative, Kant advised us to act according to universal laws [33-35]. Since we make decisions voluntarily and independently, we acknowledge and accept the outcome dominated by pure reason; with our autonomy the decision we make is the best that we can [16].

Kant reminds us that we are rational beings. Kant further warns us that we are governed by the laws of reason, not by regulation of nature. Accordingly, we can yearn for the world being a location of dissimilar beings gathering and living together, and following regulations and dealing with each other peacefully [17]. Thus, according to Kant, we respect the autonomy of the patient, including persons diagnosed with a mental illness, and their relatives. We must pay sufficient attention to how behaviour of the persons diagnosed with mental illness affect their relatives, classmates, teachers, neighbors, their respective victims and the latter's relatives, their respective communities and the society as a whole, etc. The issue of morality and ethics should be taken seriously $[36,37]$. Kant advised us that there is one morality but there are many types of duties. Kant correctly asserts that sensation is not knowledge; and that the mind is the active agent that creates our knowledge. Kant's helpful analysis has divided all data into the levels of sensation, perception and ideas. Kant taught us 'humanity'; this helps us to understand human behaviour and misbehaviour. In this regard, Kant's philosophy broadens our vision of both the capacity and limitation of mankind.

In addition, this author deliberates that the study of variables affecting culture that focuses primarily on the 'macrosystem factor' is important as well. These variables include the following: family variables, religious beliefs, e.g. the, the variables (factors) of the societal structure and their effect on individuals and family (e.g. the case examples of Smith and Yates), etc. An analysis without considering the role and factor of culture, the macrosystem variables affecting culture and the effect of culture on behaviour, will be incomplete. The limitation of an incomplete analysis lacking the aforementioned is clear $[38,39]$.

\section{Some Related Key Issues with Probable Answers}

This section focuses on following areas: (1) morality and "What if everybody did it?" (2) Kant's theory of mind with its application on understanding behaviours of the two perpetrators discussed. 
A brief sketch of the basic aspects of the aforesaid issues is as follows. A preliminary exploration of the challenges by those issues are also provided as follow.

\section{The issue of morality and "what if everybody did it?"}

Kant did not supply a phenomenological description of consciousness. Karl Leonhard Reinhold, an Austrian philosopher [18] contends that Kant should have indicated the essential detail of consciousness that is vital in formulating cognition per se possible. Nevertheless, Kant's Theory of the Human Faculty of Representation described the major portions and characteristics of consciousness. Reinhold concentrates on the moral problems that Kant mentions in the final segment of Critique of Pure Reason. Reinhold focuses his attention to the epistemological aspects of the initial and central portions of the same Critique $[40,41]$.

On the other hand, Kant's famous and disproportional serious concept of morality acts on the motive of duty. Kant contends that morality is not to progress the doctrine of how we make ourselves happy, but how we make ourselves worthy of happiness. We can discover our duties by checking our maxims against Kant's categorical imperative: 'Act only on that maxim through which we can also at the meanwhile will that it should become a universal law.'

Note that Kant's principle of universalism in ethics is often referred to in the form of question as following:

"What if everybody did it?"

In this light, let us assess the behaviour of the two perpetrators discussed in light of Kant's theory of mind.

\section{Kant's theory of mind with its application on understanding the behaviours of two perpetrators}

That explored, Ameriks [16] conversely evaluates the themes handled in some Kant's publications. Kant has developed a "Theory of Mind" that ensues to be both more justifiable and more opposed to the supernatural element in Scripture than is accepted by most other interpreters. It is a theory that plays a great function for realizing Kant's philosophy of the mind as a sum total $[42,43]$.

\section{Several questions remain as following}

There are behavioural manifestations of the two perpetrators discussed in this article. Yates and Smith respectively exhibit different behaviours.

In fact, the real world is not responsible for our behaviour. With theoretical examination, we can observe that Kant critically analyzes pure reason. Kant rejects the view of Locke and Hume that all our knowledge is derived from senses. Nonetheless, Kant agrees with Hume's opinion that absolute certainty of knowledge is not possible, if knowledge comes from sensation. The Scottish philosopher David Hume (1711-1776) developed a philosophy of "mitigated skepticism," which remains a viable alternative to the systems of rationalism, empiricism, and idealism (Hume). Regardless of whether the theory of knowledge is based on Kant or both Locke and Hume or not, an independent real world really does not owe us any promise of regularity of behaviours [44]. In reality, we could feel an inducement at one location, and another at a different one. There is no promise of either regularity or association of behaviour. Kant's Critique is an analysis of the derivation and development of concepts and the hereditary organization of the mind. Such an analysis can help us understand better the respective behaviours of the two perpetrators discussed in this study, as well, other persons diagnosed with mental illness, their respective family, all victims and their respective own family.

Kant was strongly and deeply critical of the use of examples as moral standards, because such standards depend on our feelings toward morals more than our rational power. The aforementioned will be further discussed in the section of categorical imperative for illustrative purposes.

According to Kant, the dialectic threatens the truth by deceiving those that fail to identify the a priori absoluteness of certain principles. Kant places a priori first, and from it deduced morality. The actions of any rational being can be ascertained from a moral standpoint. According to Kant, the highest aim of morality consists in generating an impartial world in which happiness is 'in exact proportion' to morality' [17].

In Kant's allegory, freedom means the ability to select between the obvious needs of survival and admiration for the inestimable pride of humans. Kant felt that as man's knowledge developed, man would recognize his own relative insignificance in the universe. At the same time, such a self-understanding and reflection would allow the moral law within him to continue to expand and further develop maxim [46]. Moral beings with infinite value, we can realize the meaning and selfesteem of our standing in the universe. With such an infinite perspective, Kant precedes the maxim for us, and concludes that pure reason can define right and good. All moral philosophers do not all agree with any premise such as merely "do no harm" or "hurt no one" in the usual and customary practice of bioethics. Rather, they prefer one to do no harm, but that is not good enough morally. It is more important to help all, including those who are persons diagnosed with a mental illness, and their respective family [46].

Kant advises us to "act only according to that maxim whereby you can at the same time will that it should become a universal law." This is best known as the first formulation [19]. A criterion of morality, and of ethics is that an action is moral if it is enviable, and it is a universal rule of behaviour.

Finally, in order to sum up important epistemological and ethical themes in Kant's philosophy, from the rationalist point of view, discussions follow. When we mention "rationalist", usually we rely in the broadest and weakest sense; but when we refer to "Kant", likely we purposely mean "rationalist" in a rather strong meaning. That clarified, the ascription of criminal responsibility is related to the ascription of ability to reflexive thinking, that is, to reject immediate behaviour for a while and to "play forward" behavioral options in a virtual space ("if one does A, then B may take place", and so on). It is supposed that most adult humans possess this ability. It appears that a very potent rationalism like Kant's theory is necessary under this circumstance [47].

Pre-meditation is a strong factor in our modern court cases in proving guilt and is self-defence in proving innocence. Lawyers who try to cover from lack of accepting responsibility for one's actions often justify by introducing alcohol or drugs use or so called "bi-polar" syndrome.

Why, nowadays, there are jails full of mentally ill patients? Due to individual rights, in the US, laws state that we cannot force people to seek treatment. Often they even have to commit a crime before they 
Citation: Tang B (2015) Recognizing Criminal Behavior (Filicide) of Persons Diagnosed with Mental Illness: An Analysis on the Intentionality and a Philosophical Disclosure on Ethics and Morality. J Clin Res Bioeth 6: 239. doi:10.4172/2155-9627.1000239

Page 7 of 8

can be remanded for psychiatric assessment. Fortunately, there have been changes through the years with regard to community treatment laws. For example, mental illness is viewed differently these days than it was earlier, as well our contemporary view of mental illness has affected the legal treatment of the mentally ill. Hence it is important to clearly establish the "danger to self or others criteria" in order to ensure that the mentally ill people get treatment [48].

It is obvious that the aforesaid two US perpetrators' conduct in their respective case examples was immoral. Nevertheless, will neuroscientific knowledge affect our moral conduct?

Probably, it may not influence our conduct but it might affect the extent to which we are held responsible for our conduct. For example, in Smith and Yates' cases, mental illness is viewed quite differently than it was in earlier times. Our contemporary view of mental illness has influenced our legal treatment of the mentally ill. No aggressive actions were taken due to the limitations of the individual-right law. Any failure to act may finally led to a major disaster. Ms Andrea Yates' cases are a typical illustration of the disturbance of mindset.

The bottom line seems to be as following: some researcher looks at the modern belief that the mind is the same thing as the brain, and therefore the mind appears to consist of genetic and chemical processes. Contrary to this notion is the more common sense views that our mind is made up of experiences of the world. While the brain may be the material home of the mind, it is not the mind itself $[45,49]$.

On the other hand, neuroscience will, as well, influence how we think about morality and about mental illness. Many people believe that something non-physical, like a soul with contra-causal free will, is ultimately responsible for behavior. Neuroscience shows that the brain is responsible for behavior, not the soul, so we don't deserve punishment for wrongdoing in the way that many people think the soul deserves to be punished. This might change our beliefs about morality, our attitudes towards each other, and the mentally ill, (e.g. Yates, and Smith), our responsibility practices, (e.g. how we treat the mentally ill in the criminal justice system) [20].

\section{Conclusion}

In summary, two media-oriented case histories of murder in the US are explored to investigate the interaction between the brain and the mind. A number of insights have been offered.

Kant's theory of the mind and his categorical imperative may enhance what has been known in medicine of the issue between brain and mind.

As for those two patients, Susan Smith, and Andrea Yates (both drowned their children), their respective behaviours should have been be identified early in their course of care. Such recognition should be preceded by a well-planned detection of the crisis and appropriate staffing. Additionally, law enforcement protection should be secured. An outside observer (especially one who does not interact with a person) can actually give very little insight into the inner workings of a person's mind or their subjective sense of morality, purpose, values, or intentions. Observation from an outside observer or so called eyewitness can hardly provide any visual perspective and dynamics of the mind of persons diagnosed with mental illness.

There are several components of this article coherent to have supported the remaining and final part of central argument as follows, and, the author has already explored the nature of morality, the morality of law-breaking behavior, the merits of considering intentionality when evaluating guilt or interpreting laws, critiquing a justice system that employs merely on binary verdicts (guilty or not guilty) rather than on an entire spectrum of culpability, and the ways in which society views mental illness in the context of constant and uniform surveillance or more specifically once crimes have been committed in determining guilt and punishment. The remaining and final portion of such a central argument lies on when people commit crimes and have severe mental illness such as a psychotic disorder, how do we understand their behaviors and the ways in which culpability is determined should be based on a complex web of assumptions about their capacity to think rationally and abstractly, understand morality, and act with intentionality (based on some key theorists such as Dennett, Searles, Brenato, etc.). This argument has the potential to offer bountifully to the combined field of moralities, ethics, laws, and mental health, as well as public health.

\section{References}

1. Locke J (1689) An essay concerning human understanding. Harvester Press; Atlantic Highlands, NJ, Humanities Press.

2. Sheth DN, Bhagwate MR, Sharma N (2005) Curious clicks-Sigmund Freud. Journal of Postgraduate Medicine 51: 240-241.

3. Western D (1998) The scientific legacy of Sigmund Freud: Toward a psychodynamically informed psychological science. Psychological Bulletin 124: 333-371.

4. Greer S (2002) Freud's "bad conscience": The case of Nietzsche's Genealogy. J Hist Behav Sci 38: 303-315.

5. Griffin DR (2000) Religion and Scientific Naturalism: Overcoming the Conflicts. International Journal for Philosophy of Religion 49: 197-200.

6. Resnick PJ (1969) Child murder by parents: a psychiatric review of filicide. Am J Psychiatry 126: 325-334.

7. Brown RK (2008) Hoaxes Signal the State of Our Racial Fears. Orlando Sentinel.

8. Harris C (1996) Myths of Race and Gender in the Trials of O.J. Simpson and Susan Smith-Spectacles of Our Times. Washburn Law Journal 35: 225.

9. Suzanne O'Malley (2004) Are You Alone? The Unspeakable Crime of Andrea Yates. Simon \& Schuster, pp.117, 118, 170, 240.

10. Sheri LB (2003) Mothers Who Kill Their Children and Postpartum Psychosis. Southwestern University Law Review 32: 451.

11. Fodor J (1975) Language of thought, Harvard University Press.

12. Goodman N (1961) About. Mind 70: 1-24.

13. Putman H (1958) Formalization of the concept "about". Philosophy of Science 25: 125-130.

14. Brenato F (1995) Psychology from an Empirical Standpoint. Routledge, NY, p. 88-89.

15. Jordan S, Ghin, M (2007) The Role of Control in a Science of Consciousness: Causality, Regulation and Self-Sustainment. Journal of Consciousness Studies 14: 177-197.

16. Ameriks K, Kant I (1995) The Cambridge Dictionary of Philosophy. Cambridge University Press, Cambridge, p. 460-466.

17. Kant I (1993) The critique of practical reason. NY Library of arts, p. 117.

18. Reinhold K, Ameriks K, Hebbeler J (2006) Letters on the Kantian Philosophy. Cambridge University Press.

19. Kant I (1785) Grounding for the Metaphysics of Morals.

20. Clark T (2005) Killing the Observer. Journal of Consciousness Studies 12: 38-59.

21. Karl A (1982) Kants' theory of mind: An Analysis of the Paralogisms of Pure Reason. Clarendon Press, Oxford.

22. David C (1992) The Conscious Mind. Oxford University Press.

23. Clark T. Medicine and Morality: Resolving the Conflicts. 
Citation: Tang B (2015) Recognizing Criminal Behavior (Filicide) of Persons Diagnosed with Mental Illness: An Analysis on the Intentionality and a Philosophical Disclosure on Ethics and Morality. J Clin Res Bioeth 6: 239. doi:10.4172/2155-9627.1000239

Page 8 of 8

24. Dennett D (1987) The Intentional Stance. MIT Press, p. 17.

25. Dennett D (1991) Consciousness explained. Little Brown and co, NYC, p. 458.

26. Fielding H (2007) Forbes Book of Business Quotations. Cambridge University Press, Cambridge, New York, p. 33.

27. Henry C, Etain B, Godin O, Dargel AA, Azorin JM, et al. (2015) Bipolar patients referred to specialized services of care: Not resistant but impaired by sub-syndromal symptoms. Results from the FACE-BD cohort. Aust N Z J Psychiatry 49: 898-905.

28. KTRK-News, Houston, January 26, 2007

29. Irwan TH (1998) Aristotle. Routledge Encyclopedia of Philosophy. Routledge, New York.

30. Thomas KM (1977) Social Interaction. CV Mosby, Saint Louisy.

31. Liem M, Koenraadt F (2008) Filicide: a comparative study of maternal versus paternal child homicide. Crim Behav Ment Health 18: 166-176.

32. Macer DR (2002) The next challenge is to map the human mind. Nature 420: 121.

33. McLeisch, Cole K (1999) Aristotle: The Great Philosophers. Routledge, p. 5.

34. MuggleNet (2009) Harry Potter and the Chamber of Secrets, p. 333.

35. Jordan JS (2008) Wild agency: nested intentionalities in cognitive neuroscience and archaeology. Philos Trans R Soc Lond B Biol Sci 363: 1981-1991.

36. Thinly F (1896) Kant's Inaugural Dissertation of 1770 by Eckoff WJ. The Philosophical Review 5: 668-669.

37. Kant I, Smith KN (1965) Translated from Kant I Critique of Pure Reason (1787) (2ndedn.) St. Martin's Press, New York, USA, p. 34.
38. Kant I, Smith KN (1965) Translated from Kant I Critique of Pure Reason (1787) (2ndedn.) St. Martin's Press, New York, USA, p. 75.

39. Maat K (2007) The Moral Ideal in Ancient Egypt. African Studies: History, Politics, Economics and Culture, KTRK-News, Houston.

40. Lecompte M, Dworkin A (1991) Giving Up on School: Student dropouts and teacher burnouts. Corwin Press Newbury Park, CA.

41. Locke J (1689) An essay concerning human understanding. Harvester Press, Atlantic Highlands, NJ, USA.

42. Howard JM, Hess W, Traverso W (1998) Johann Georg Wirsüng (1589-1643) and the pancreatic duct: the prosector of Padua, Italy. J Am Coll Surg 187: 201-211.

43. Reznick PJ (1970) A Meta-Synthesis of Filicide Classification Systems: The Seminal Work: Classification of Filicide by Motive.

44. Ross ED, Monnot M (2008) Neurology of affective prosody and its functional-anatomic organization in right hemisphere. Brain Lang 104: 51-74.

45. Rowling JK (1999) Harry Potter and the chamber of secrets. Levine Books, New York, NY.

46. Salif al-ranbi (2007) Banipal.

47. Solso R (2005) The Psychology of Art and the Evolution of the Conscious Brain. MIT Press, Cambridge, USA.

48. Spitz DJ (2006) Investigation of Bodies in Water. In: Spitz and Fisher's medicolegal investigation of death: Guideline for the Application of Pathology to Crime Investigations (4thedn.) Charles C. Thomas. Spring 5: 39-49.

49. Wolpe PR, Foster KR, Langleben DD (2005) Emerging neurotechnologies for lie-detection: promises and perils. Am J Bioeth 5: 39-49. 